\title{
EL BLOQUEO REGISTRAL POR PRESUNTA FALSIFICACION DE DOCUMENTOS
}

\author{
The Blocking for Presumed Falsification of Documents
}

\section{RESUMEN}

El bloqueo registral por presunta falsificación de documentos, es una medida administrativa registral, que se tramita en la SUNARP, y cuya finalidad es que, de forma temporal por 120 días hábiles, no se pueda inscribir ningún acto, derecho o contrato, en la partida registral, por existir un asiento registral inscrito en mérito a un documento presuntamente falsificado.

PALABRAS CLAVES: Bloquear - registral falsificación - documentos.
Miguel Ángel Tinajeros Arteta ${ }^{1}$

\begin{abstract}
Registers blocking for alleged forgery of documents is an administrative-registry measure. It is processed in the SUNARP and its purpose is not to register any act, law or contract temporarily, by 120 days, the reason for this is that there is a registry seat registered in merit to an allegedly forged document.
\end{abstract}

KEY WORDS: Block - registry - forgery documents.

\section{INTRODUCCIÓN}

El presente trabajo, tiene como objetivo hacer un análisis descriptivo sobre el procedimiento administrativo consistente en el bloqueo por presunta falsificación de documentos, que se tramita ante los órganos descentralizados de la Superintendencia Nacional de los Registros Públicos.

En nuestro país, en los últimos años la delincuencia ha venido ganando espacio, en los diversos aspectos de la vida, tanto, respecto del simple atentado contra la propiedad, hasta las más sofisticadas estafas y defraudaciones cometidas por el crimen organizado.

Estas organizaciones criminales intentan lesionar la seguridad jurídica protegida por la SUNARP, y en algunos casos - felizmente muy escasos estas organizaciones han logrado vulnerarla, sobre todo por los falsificadores que cada vez son más expertos, y que utilizan la más avanzada

\footnotetext{
${ }^{1}$ Abogado graduado en la Universidad Nacional de San Antonio Abad del Cusco, becario de la Agencia Española de Cooperación Internacional, con Maestría en Derecho Civil y Procesal Civil en la Universidad Nacional de San Antonio Abad del Cusco, estudios de Doctorado en Derecho en la Universidad del País Vasco. Ha ejercido catedra universitaria en las asignaturas de Derecho Laboral, Derecho Constitucional y Derecho Registral, en la Universidad Nacional de San Antonio Abad del Cusco y Universidad Alas Peruanas. Jefe de la Unidad de Asesoría Jurídica de la Zona Registral X Sede Cusco. Correo electrónico: migueltinajeros@hotmail.com
} 
tecnología para pretender inscripciones con documentación falsa.

En tal sentido se aprecia que la seguridad jurídica es importante para el desarrollo de la sociedad, como manifestación de la seguridad que surgió en el estado de derecho con requisito de certeza y estabilidad, y puede ser visto como contrapeso de los riesgos de la libertad contractual y como factor de confianza necesario para el desarrollo estable del tráfico jurídico (Huerta, 2013, p. 13). Ante esta situación, la SUNARP, no puede quedarse impávida, ni tranquila, $\mathrm{y}$ ha implementado una serie de mecanismos destinados a impedir la inscripción con documentos falsificados, y de haber sucedido esta, ha establecido, mecanismos que permiten bloquear de manera temporal dichas inscripciones, como es el caso del bloqueo por presunta falsificación de documentos.

De este modo, la SUNARP brinda a la ciudadanía facilidades y mecanismos a fin de proteger los derechos adquiridos, de personas o grupos delincuenciales que presentan documentación falsificada a fin de obtener beneficios indebidos e ilegales.

En ese entender, analizaremos la normatividad legal que regula el procedimiento administrativo de bloqueo por presunta falsificación de documentos, el cual está regulado por la Directiva 001-2012-SUNARP-SN, que fue aprobada por la Resolución $\mathrm{N}^{\circ}$ 019-2012SUNARP-SN y modificada por la Resolución $\mathrm{N}^{\circ}$ 256-2012-SUNARP-SN.

\section{EL DERECHO REGISTRAL}

No podemos desarrollar nuestro tema, sin antes hacer mención a algunos conceptos importantes, dentro de ellos el concepto de Derecho Registral, que viene a ser una disciplina autónoma del Derecho Civil, con el cual tiene estrecha relación, pero también independencia.El Derecho Registral es el conjunto de normas jurídicas vigentes y de principios registrales, que regulan la organización y funcionamiento de los
Registros Públicos, así como las anotaciones preventivas y las inscripciones en los diferentes registros que forman parte del sistema registral en cada estado, en un determinado tiempo y espacio, y su relación con terceros (Amado, 2017, p. 13).

Si bien este concepto es bastante amplio, no se ha considerado en el mismo los trámites administrativos, como es el caso del cierre de partidas por duplicidad, la cancelación administrativa y el propio bloqueo por la presunta falsificación de documentos, por lo que el concepto de derecho registral debe ser ampliado.

\section{EL BLOQUEO REGISTRAL}

El bloqueo registral es un concepto eminentemente registral, el cual tiene sus inicios todavía en el Decreto Ley 18278 del 19 de mayo del 1970, por el cual precisamente se crea esta figura jurídica, norma que actualmente se encuentra vigente y tiene por finalidad favorecer a las personas que lo soliciten, la futura inscripción de un acto o contrato que se viene celebrando o se celebrará, en ese entender garantiza la prioridad de la inscripción.

El bloqueo registral no bloquea, lo que hace es resguardar la prioridad de inscripción sobre otros títulos ingresados a la partida registral del inmueble...Esto no significa que se bloqueará la partida del inmueble, lo que hará el bloqueo es resguardar la prioridad de la inscripción definitiva del acto rogado (Amado, 2017, p. 573).

El bloqueo registral debe terminar con su anotación, no es una inscripción conforme lo veremos más adelante, y permitirá que en el plazo establecido no se pueda realizar ningún trámite más que el que motivo el bloqueo, es así que el bloqueo registral es temporal y no es definitivo, en este caso tiene un plazo de vigencia de 60 días, así mismo es oponible a terceros en mérito a la publicidad que otorga los registros públicos de dicho acto y otorga prioridad al acto que finalmente será inscrito. 


\section{ANOTACIÓN O INSCRIPCIÓN.}

Muchas veces los usuarios del Registro Público confunden, o por lo menos utilizan de manera indistinta los conceptos de anotación e inscripción, como si fueran sinónimos, lo que en el mundo del derecho son dos conceptos diferentes, por eso, es que la norma jurídica utiliza estos conceptos por separado y como consecuencia de distintos trámites.

El artículo 64 del Reglamento General de los Registros Públicos, ha establecido una definición de anotación preventiva, al prescribir: "Las anotaciones preventivas son asientos provisionales y transitorios que tienen por finalidad reservar la prioridad y advertir la existencia de una eventual causa de modificación del acto o derecho inscrito".

Dentro de las notas características de las anotaciones preventivas, además de su naturaleza orientada a obtener una inscripción definitiva y su eficacia limitada, se encuentra la temporalidad de las mismas, puesto que a diferencia de las inscripciones nacen con una duración temporalmente limitada (Gonzales, 2002, p. $330)$.

El artículo 65 del Reglamento General de los Registros Públicos, establece que actos y derechos son susceptibles de anotación preventiva, entre ellos encontramos: a) Las demandas y demás medidas cautelares; b) Las resoluciones judiciales que no den mérito a una inscripción definitiva; c) Los títulos cuya inscripción no pueda efectuarse por no estar inscrito el derecho de donde emane; d) Los títulos cuya inscripción no pueda efectuarse porque adolecen de defecto subsanable; e) Los títulos que, en cualquier otro caso, deben anotarse conforme a disposiciones especiales. El bloqueo por presunta falsificación de documentos se encuentra en este último caso, por tratarse de una Directiva específica.

La anotación preventiva no es el contrapeso de la fe pública registral; pues en muchos casos ese principio no es aplicable, pero a pesar de ello la anotación está presente en mundo jurídicoregistral. En realidad, si partimos del antecedente que el Registro es un reflejo de las diversas situaciones jurídicas sustantivas, entonces el consecuente es que la anotación preventiva, también acerca la vida al registro, especialmente cuando tenemos situaciones interinas 0 tambaleantes, pero que existen en tal condición. El Registro, salvo que pretenda convertirse en forzosa "verdad oficial", y por tanto en falsa apariencia, no puede negarse a acoger las situaciones que presenten tales características. Por ejemplo, la demanda judicial ingresa a la publicidad por medio de la anotación, ya que este mecanismo permite que el registro refleje un litigio o controversia sobre el bien, cuyo resultado puede ser impredecible, pero que hoy existe como conflicto y es menester anunciarlo de ese modo (Gonzales, 2012a, p.291).

En consecuencia, las anotaciones preventivas ayudan a la finalidad primera y esencial de todo registro: exponer la realidad jurídica, por más dura y problemática que esta fuese. Uno de los mayores errores de los extremistas registrales es pretender que la publicidad debe ser limpia, clara y coherente; lo que lleva a falsear las cosas, pues la realidad puede ser oscura, ambigua y litigiosa. El Registro no cambia la vida, solo la refleja, la hace de conocimiento general. Ese es su primer y más importante objetivo (Gonzales, 2012, p.291).

La anotación preventiva, al ser pública, permite el conocimiento de su contenido a cualquier ciudadano.

Una de las anotaciones que más se utiliza, es el bloqueo registral, cuya finalidad es retrotraer los efectos de la inscripción a la fecha de la anotación, de tal forma que quien venda un bien, no realice otro acto vinculado a dicho bien, garantizando la transacción y se evite los fraudes. En nuestro ordenamiento se evita este riesgo a través de una eficacia retroactiva de la futura inscripción, la misma que se computa desde el ingreso en el registro de una reserva de espacio registral, para lo cual se requiere adjuntar el documento privado que sustente la transferencia (minuta). Este bloqueo se considera una anotación preventiva de breve duración (sesenta 
días), siendo que en ese lapso debe formalizarse el documento público notarial de la transferencia $\mathrm{o}$, en caso contrario, la anotación caduca automáticamente. De acuerdo con una de las clasificaciones vistas en el apartado anterior, el bloqueo registral es una típica anotación que publica sin constituir, anunciando un derecho real al que falta la documentación pública.

La inscripción, viene a ser el resultado de la calificación registral, lo que se conoce como calificación registral positiva, por el cual se acepta que el acto, contrato o derecho tenga acceso a la protección que brinda el Registro Público, por haber cumplido con los requisitos establecidos por la norma y conforme a la aplicación de los principios registrales establecidos en el título preliminar del Reglamento General de los Registros Públicos; es la incorporación del título rogado al manto de seguridad que otorga el Registro Público.

De los párrafos anteriores, se tiene que el bloqueo por presunta falsificación de documentos, viene a ser una anotación y no una inscripción, por tanto, tendrá las características de dicha figura jurídica.

\section{PUBLICIDAD DE LA ANOTACIÓN DEL BLOQUEO POR PRESUNTA FALSIFICACIÓN DE DOCUMENTOS.}

La publicidad, en el ámbito del Derecho Registral implica la difusión de la inscripción o anotación, cuya finalidad es poner en conocimiento de los usuarios determinadas situaciones jurídicas, que garantizan la seguridad jurídica; dentro de las principales características de la publicidad registral se tiene que esta es: una expresión exterior del registro, cognoscible, de naturaleza jurídica y eficaz.

El artículo 2012 del Código Civil Peruano, prescribe: Se presume, sin admitirse prueba en contrario, que toda persona tiene conocimiento del contenido de las inscripciones, de lo que se desprende que la información contenida en el registro es conocida por todas las personas.
En ese entender ningún tercero podrá alegar el desconocimiento o la ignorancia del contenido de lo inscrito, en razón de que siempre tuvieron la posibilidad de conocer y saber su contenido. En ese mismo sentido todo aquello que no está publicitado no puede perjudicarlo, y tampoco puede oponérsele, en razón de que no estaba en posibilidad de conocerlo.

La publicidad, en sentido amplio y general, es el conjunto de medios que se emplean para divulgar y extender el conocimiento o noticia de determinadas situaciones o acontecimientos con el fin de hacerlo llegar a todos, de modo que tales situaciones o acontecimientos, en cuanto objeto de publicidad, adquirirán la calidad o estado de públicas, esto es, serán notorias, manifiestas y patentes para todos.

La publicidad en sentido amplio y general es el conjunto de medios que se emplean para divulgar y extender el conocimiento o noticia de determinadas situaciones o acontecimientos con el fin de hacerlo llegar a todos, de modo que estos en cuanto objeto de publicidad adquirirán la calidad o estado de públicas; esto es serán notorias, manifiestas y patentes para todas. Así la publicidad se opone a la clandestinidad, en tanto la primera supone divulgación y conocimiento, mientras la segunda ocultación y desconocimiento (Huerta, 2013, p, 19).

Encontramos, pues, en la publicidad dos elementos unidos de manera inescindible, aunque a veces con fines didácticos procuremos separarlos: por una parte la publicidad produce ciertos efectos sustantivos (constitución, oponibilidad a terceros, seguridad del tráfico), y mirada desde este ángulo se denomina publicidad material, por otra parte, el legislador, para lograr esos fines, organiza un sistema en el que se emplean ciertos instrumentos o herramientas publicitarias que reciben el nombre de publicidad formal (Moisset 2015, p. 311).

Por tanto, la publicidad registral necesita, como contrapartida, que cualquier persona pueda acceder de forma general, simple y eficaz a los 
datos inscritos. El acceso general significa que todos los sujetos puedan conocer la información general, sea de forma libre, sea a través del filtro de la prueba de un interés lícito para buscar información. Nuestro país sigue el modelo libre, pues a nadie se le pregunta su motivación para obtener los datos que busca. Incluso el acceso a la información se hace en línea, por lo cual no existe necesidad alguna de justificar la solicitud (Gonzales, 2012, p.147).

En ese entender, el acceso a la anotación del bloqueo por presunta falsificación de documentos, es libre y se realiza sin presentar ninguna justificación de las razones o motivos para su obtención.

\section{EL BLOQUEO POR PRESUNTA FALSIFICACIÓN DE DOCUMENTOS.}

Como parte de la política institucional de la SUNARP, es la ampliación de nuevos servicios, acorde con los nuevos retos que nos brinda la sociedad y las necesidades del usuario, así ha creado una nueva figura jurídica, aunque más que registral de naturaleza administrativa, que viene a ser el bloqueo por presunta falsificación de documentos.

Una novedad es el bloqueo por presunta falsificación de documentos, máxime cuando en estos tiempos, hemos sido testigos de mafias que por alguna razón se han apropiado ilícitamente de inmuebles de manera ilegal, ya sea en complicidad de las autoridades administrativas, notariales, judiciales o de artimañas jurídicas, frente a ello, la SUNARP, que no puede estar ajena al tema ha regulado a través de resoluciones esta figura jurídica registral (Amado, 2017, p, 578).

El bloqueo por presunta falsificación de documentos, consiste en una anotación en la partida registral para publicitar sobre la detección, en sede registral, de la existencia de un asiento registral extendido en mérito de un título que presuntamente contiene el documento falsificado.

El bloqueo por presunta falsificación de documentos, constituye un mecanismo temporal de prevención emitido en sede registral, a fin de poner en conocimiento de las personas que actúan en el tráfico jurídico, respecto a asientos registrales que estén cuestionados en sede registral. Además, de asegurar el cumplimiento de la decisión provisional (medida cautelar) y la decisión definitiva (sentencia, desde luego después de un proceso judicial) a emitirse por el Poder Judicial, mediante la cual se declare la nulidad de los asientos o, eventualmente, de toda partida registral, debido a que las inscripciones se sustentaron en un título que contiene presuntamente documentos falsificados.

En cuanto al futuro proceso judicial, este puede ser instado por el usuario perjudicado por la inscripción aparentemente realizada mediante la falsificación de documentos, sin embargo, la propia norma ha establecido la obligación de la Procuraduría Pública de la SUNARP de presentar la respectiva denuncia ante las instancias judiciales respectiva, pero no solo eso, ha establecido la prioridad de la atención de estos trámites, con lo cual se pretende evitar cualquier caducidad de la anotación del bloque por presunta falsificación de documentos, y lograr las medidas cautelares correspondientes.

\section{FINALIDAD.}

Del concepto vertido líneas arriba, se tiene que la finalidad del bloqueo por presunta falsificación de documento, es poner en conocimiento que un asiento registral se ha extendido sobre la base de un título que contiene presuntamente documento falsificado; y además garantizar la prioridad de la eventual medida cautelar dictada por el órgano jurisdiccional.

\section{LA FALSIFICACIÓN DE DOCUMENTOS.}

En tiempos actuales, en donde la economía se desarrolla sin conocer fronteras, se presentan 
muchas figuras en el desarrollo de la sociedad, una de ellas es el denominado boom inmobiliario, entendido este como aquel fenómeno temporal, en el cual en un periodo corto se realiza la construcción de viviendas y edificaciones que sobre pasan los estándares normales de demanda, el cual al igual que en otras latitudes se ha presentado en nuestro país.

El boom inmobiliario por el que atraviesa nuestro país, se ve reflejado en la creciente demanda de inmuebles. Ha convertido a los Registros Públicos en un actor fundamental para dotar de seguridad jurídica a las transferencias que sobre dichos bienes se realizan constantemente en el mercado (Amado, 2017, p, 599).

Por tanto, uno de los blancos de la delincuencia organizada, viene a ser el Registro Público. La seguridad jurídica, que otorga el registro en la actualidad se ha visto amenazada por personas e incluso agrupaciones presuntamente delictivas que presentan documentación falsificada, a fin de obtener beneficios indebidos, perjudicando a personas que adquieren derechos confiando en la información que brinda registros (Amado, 2017, p. 599).

En ese entender los Registros Públicos se ven amenazados por el actuar delictivo, que tiene por finalidad introducir documentación falsificada a fin de obtener beneficios ilegales.

Existen aparentemente numerosas redes delincuenciales dedicadas a la búsqueda y ubicación de inmuebles abandonados, desocupados, de herencia, de ancianos, de personas que han fallecido, que no revisan la documentación en los Registros Públicos, y de quienes están en el extranjero. Ubicado el inmueble, se pretende, y se logra venderlo, sin el consentimiento del propietario (Amado, 2017, p. 599).

\subsection{Falsedad y falsificación.}

Falsificar es adulterar, corromper o contrahacer una cosa material. Así decimos que alguien falsificó moneda, un cuadro o un testamente, y no que los falseó: en esencia la falsificación es una imitación, es imitación de lo auténtico, de lo genuino, es decir, de ciertos signos que caracterizan al modelo (Urtecho, 2015, p.174).

\subsection{Formas típicas de falsedad.}

\subsubsection{Falsedad material}

Es aquella que recae sobre un objeto, que puede ser el documento o sobre su contenido, a través de lo que se conoce como imitaciones, o creaciones.

Por eso la falsedad material puede efectuarse por el hecho de hacer un documento falso, en todo o en parte, por el hecho de adulterar un documento verdadero; y por el de suprimir o destruir, en todo o en parte, un documento. Nuestro Código Penal lo contempla en el artículo 427 (Urtecho, 2015, p.175).

\subsubsection{Falsedad ideológica}

También conocida con falsedad ideal, que se presenta cuando en un documento elaborado por las autoridades competentes, se incluyen hechos falsos, es decir, se realiza sobre el contenido del documento, sin atentar contra los elementos de su autenticidad, ni de su formalidad.

En la falsedad ideológica, la realización externa es siempre real y el documento es confeccionado por quién y en la forma que es debido, es decir, de acuerdo a Ley. El hecho punible resulta por la consecuencia de que esa correcta exteriorización genera una distorsión de la verdad que se desprende del documento.

\subsection{EI bien jurídico protegido en los delitos de falsedad documental.}

El bien jurídico protegido, es un concepto que en el ámbito del derecho penal implica el estado de valoración que la norma jurídica la otorga, en base a intereses individuales o de la colectividad que merecen protección jurídica.

"Así, es de larga tradición, la posición que considera a la fe pública -originaria en la doctrina italiana- como el objeto de protección penal, que vendría a entenderse como la amplia confianza 
que se tiene en el tráfico jurídico y social documentario" (Urtecho, 2015, p. 202). En esta misma línea el legislador de nuestro país, ha considerado como el bien jurídico protegido en estos delitos a la fe pública.

\subsection{El concepto de documento}

"El objeto material sobre el que recae la falsedad es el documento; así se estima de la acción comitiva en el tipo penal previsto en el primer y segundo párrafo del artículo 427 del Código Penal: que debe recaer sobre un documento" (Urtecho, 2015, p. 217). En una concepción amplia podemos decir que, el documento es la materialización de un hecho, acto, dato o narración, que pueda contener una declaración o un pensamiento que tiene una consecuencia jurídica.

De la revisión del texto del Código Penal peruano, se tiene que este no realiza una definición de documento, por tal motivo es necesario recurrir a otro texto normativo, en este caso se debe tomar en cuenta lo normado por el Código Procesal Civil, en efecto el artículo 233 de dicho cuerpo normativo, define al documento como todo escrito $\mathrm{u}$ objeto que sirve para acreditar un hecho.

Así el documento es un objeto material, que necesariamente tiene un originen humano, que puede representar actualmente y en el futuro, un hecho o varios hechos, y que tienen efectos jurídicos, también puede representar o reproducir la manifestación del pensamiento. Cuando la norma se refiere a un medio de prueba, se debe diferenciar el documento del instrumento. Se denomina documento a todo objeto que represente una manifestación del pensamiento mediante signos exteriores entendibles, mientras que instrumento, bien a ser los objetos que para entenderlos requieren la intervención de otros medios, como el peritaje o la traducción.

Por otro lado, se debe tener en cuenta que el artículo 234 del Código Procesal Civil prescribe que: Son documentos los escritos públicos o privados, los impresos, fotocopias, facsímil o fax, planos, cuadros, dibujos, fotografías, radiografías, cintas cinematográficas, micro formas tanto en la modalidad de microfilm como en la modalidad de soportes informáticos, y otras reproducciones de audio o video, la telemática en general y demás objetos que recojan, contengan o representen algún hecho, o una actividad humana o su resultado.

El documento es una declaración, que realiza una persona que figura como su autor, cuyo contenido tiene eficacia probatoria dentro del ámbito del tráfico jurídico.

La importancia del concepto documento, radica en el hecho de que este es un medio por el cual se materializa un contenido al establecerse un soporte material que permite su conservación, se puede individualizar al autor, a través de la firma, pero también, se puede individualizar a quien lo elaboró y que además sirve como un elemento de prueba al estar en el tráfico jurídico, por tanto, con consecuencias jurídicas.

Según Soler, el documento para serlo típicamente en estos delitos debe tener una significación jurídica actual, o sea, tiene que producir o ser capaz de producir efectos jurídicos, ya por constituir la prueba de un acto ocurrido y por medio del cual se haya extinguido obligaciones, facultades, etc., ya por expresar la voluntad del sujeto otorgante de obligarse en el futuro, o crear derechos $\mathrm{u}$ otorgar facultades a otro sujeto. Todos tienen que ser efectos jurídicos actuales, de lo que alguien puede prevalerse, para reclamar algo o ejercer la defensa de un interés (Urtecho, 2015, p. 232).

\subsection{Clases de documentos}

La clasificación fundamental los divide en públicos u oficiales y privados. La ley peruana, como otras legislaciones del sistema penal eurocontinental, no solo otorga un tratamiento distinto, desde el punto de vista teórico, a los documentos públicos y a los documentos privados, sino que, por ejemplo, impone una mayor sanción a la falsificación de un documento 
público, que a la falsificación de un documento privado. Esta sanción le sirve también para delimitar la tipicidad o el objeto de protección de una modalidad o clase de falsedad documental, tal como sucede con la falsedad ideológica (artículo 428), la cual se restringe a prohibir que se inserte o haga insertan en instrumento público declaraciones falsas concernientes a hechos que deban probarse con el documento (Urtecho, 2015, p. 226).

\subsubsection{Documento público}

En el concepto quedan comprendidos, en el caso peruano, los documentos enunciados por el artículo 235 del Código Procesal Civil y todos los que otorgan o refrendan funcionarios públicos o quienes desempeñan "oficios públicos" (por ejemplo, los notarios), dentro de la esfera de su competencia. En lo que cabe adicionar que la ley penal peruana, artículo 427 , asimila el carácter de documentos públicos a los transmisibles por endoso o al portador, como son los cheques, pagares, letras de cambio, etc. Asimismo, se equiparán a documento público, según el artículo 433 del Código Penal, los testamentos hológrafos y cerrado. En realidad, estos documentos tienen la categoría de privado, pero dada su transcendencia para el tráfico jurídico, el legislador los asimila en su tratamiento penal a los públicos (Urtecho, 2015, p. 227).

De lo anterior podemos concluir que los documentos públicos son todos aquellos que están autorizados por los servidores o funcionarios públicos en el ejercicio de sus funciones y de acuerdo a las formalidades que la ley exige.

\subsubsection{Documento privado}

El artículo 236 del Código Procesal Civil, precisa que: documento privado es el que no tiene las características del documento público. La legalización o certificación de un documento privado no lo convierte en público. Así tenemos contratos privados, boletos de entrada a espectáculos, facturas de agua o electricidad, fotochecks, etc. (Urtecho, 2015, p. 238).

Los documentos privados, por su propia naturaleza son elaborados por particulares, allí también radica el hecho de que, la sanción en la falsificación de dichos documentos, es menor a la establecida para los documentos públicos.

\subsection{La falsedad material}

Conforme se tiene del artículo 427 del Código Penal, el que hace en todo o en parte, un documento falso o adultera uno verdadero que pueda dar origen a derecho u obligación o servir para probar un hecho, comete el delito de falsedad material.

Se trata pues, de formas de falsedad material y propia, ya que consiste en una imitación de la verdad y que es ostensible, objetiva. El delito se configura mediante actos de falsificación, esto es, a través de la creación de un documento que se presenta como original y verdadero. Pero alternativamente, el delito también se realiza con la modificación cualitativa o cuantitativa de los contenidos de un documento verdadero, lo que implica actos de adulteración (Peña, 1990, p. $351)$.

La falsedad material tiene dos modalidades: hacer en todo o en parte un documento falso y adulterar un documento verdadero.

\subsubsection{Hacer en todo o en parte un documento falso}

"El hacer, en todo o en parte, un documento falso equivale a crear, fabricar o confeccionar un documento que no existe... requiere que su preparación o confección corra a cargo de una persona y que no exista previamente" (Urtecho, 2015, p. 238).

Hacer todo un documento falso, implica crear un documento y esta creación lesiona la autenticidad del documento, se hace un documento que no existe, a través de la imitación con la finalidad de hacer pasar por verdadero o auténtico un 
documento que no lo es. Este documento aparentemente es verás en su forma y contenido, por tanto, tiene la calidad suficiente para ingresar al tráfico jurídico.

Hacer en parte un documento falso, significa que existe un documento verás que contiene declaraciones $y$ en el cual se incluye declaraciones que el autor no declaró, es decir, ataca a la declaración que contiene el documento, en razón de que se agrega declaraciones. Un ejemplo clásico es el referido a incluir declaraciones que no existían en los espacios en blanco que tiene el documento.

\subsubsection{Adulterar un documento verdadero}

El artículo 427 del Código Penal, expresamente señala que la adulteración debe recaer sobre un documento verdadero, es decir, un documento auténtico, partiendo de que la falsedad material no se vincula con la veracidad del documento, sino con la autenticidad del mismo, la autenticidad aparece como un código genético que define la identidad y rasgo peculiar del documento (Urtecho, 2015, p. 245).

Esta adulteración viene a ser la alteración del documento verdadero, por tanto, requiere la pre existencia de un documento real y auténtico, esto quiere decir que como elemento fundamental se tiene que tener el documento verdadero y sobre el cual recaerá la adulteración. Adulterar no implica agregar, sino sustituir o suprimir, en ese entender estas vienen a ser las formas de la adulteración, la primera significa reemplazar la declaración existente por otra, pero no toda la declaración sino una parte de ella, por ejemplo, el declarante dice $\mathrm{X}$, pero se borra $\mathrm{X}$ y se reemplaza por Y. En tanto que, la supresión, es aquella operación por la cual se borra o elimina una parte del documento, o de la declaración que contiene el documento, por ejemplo, se declara $\mathrm{XY}$, y se suprime $\mathrm{Y}$, quedando únicamente $\mathrm{X}$.

Cuando la norma hace mención a la falsificación de documentos se está refiriendo a aquella conducta tipificada en el artículo 427 del Código Penal, es decir, a la falsedad material, la cual recae en la escritura misma, y puede consistir en hacerla íntegramente, $o$ en agregar $o$ en reemplazar parte de ella, es decir, la norma que regula el bloqueo por presunta falsificación de documentos, solamente se aplica en el caso de la falsedad material y no en el caso de la falsedad ideológica. Con fines didácticos nos referiremos muy brevemente a la falsedad ideológica en el numeral siguiente.

\subsection{Falsedad ideológica}

Reátegui Sánchez, citado por Urtecho Benites (2015, p. 259), sobre el concepto de falsedad ideológica nos dice:

"Se llama falsedad ideológica porque el documento no es falso en sus condiciones de existencia, sino que son falsas las ideas que en él se quieren afirmar como verdaderas. Ella puede consistir en hacer aparecer en el documento como ocurrido algo que en la realidad no ocurrió o acaeció de manera distinta; por eso, se la denomina también falsedad histórica. En la doctrina sobre el delito de falsedad de documentos, el concepto de falsedad ideológica se refiere cuando la alteración de la verdad recae en el contenido ideológico del documento, es decir, a la verdad expresada en el documento"

La falsedad de ideológica recae sobre el contenido del documento y no se altera los denominados signos de autenticidad, como es el propio documento verdadero, los otorgantes y los signos particulares, lo que no es cierto es la declaración o declaraciones que contienen.

\section{DOCUMENTOS A LOS QUE SE LES APLICA EL BLOQUEO POR PRESUNTA FALSIFICACIÓN DE DOCUMENTOS}

El bloqueo por presunta falsificación de documentos está ideado solamente para el caso de detección de asientos registrales (no ha títulos en trámite), extendidos en mérito a instrumentos públicos notariales protocolares (por ejemplo: escritura pública de compra venta de inmueble), resoluciones administrativas (como: la 
Resolución Municipal que establece la sub división del predio), documentos consulares (por ejemplo: poder otorgado ante Cónsul), resoluciones judiciales o laudos arbitrales.

\section{X. ÓRGANO COMPETENTE}

El órgano competente para el conocer y resolver el pedido de bloqueo por presunta falsificación de documentos, es la Jefatura de la Zona Registral correspondiente, por ser este, un trámite de índole administrativo que se presenta a través de una denuncia ante la mesa de partes y no se presenta como título, sin embargo, puede presentarse algún caso, como en efecto sucede que la denuncia sea presentada como título, en este caso lo que corresponde es encausar el trámite, así lo ha determinado la Resolución $\mathrm{N}^{\circ}$ 272-2013-SUNARP-TR-T, fundamento 6, que expresa: Sin embargo el Registrador en su pronunciamiento obliga al interesado a efectuar su presentación por vía regular, conforme lo dispone la directiva antes indicada, con lo cual omite la obligación que tienen las autoridades administrativas de encauzar de oficio el procedimiento administrativo ante omisiones o errores de los administrados, esto es, subsanar cualquier error u omisión que se advierta en el procedimiento de conformidad a lo establecido en el artículo 75.3 de la Ley del Procedimiento Administrativo General.

\section{PROCEDIMIENTO}

El bloqueo por presunta falsificación de documentos tiene el siguiente procedimiento:

- Inicio del procedimiento, el cual puede ser por: Denuncia especial, por parte de un tercero. Entendida la denuncia como el acto por el cual cualquier persona, en cumplimiento o no de una obligación legal, pone en conocimiento del órgano competente la existencia de un determinado hecho que pudiera justificar el inicio de un procedimiento. De ser una denuncia de parte, deberá contener la indicación de los hechos, la información que permita la constatación, el aporte de su evidencia o de su descripción para que la entidad proceda a su ubicación, así como cualquier elemento que permita su comprobación.

También se inicia el procedimiento cuando el Registrador Público, advierta que un título archivado contiene un documento falso y comunica a Jefatura Zonal de este hecho. Este caso se presente como consecuencia de la calificación registral.

Por otro lado, se puede dar el inicio del procedimiento como consecuencia de la comunicación de cualquier servidor o funcionario de la SUNARP y de cualquier otra institución pública.

El procedimiento puede que se inicie a instancia de parte, sin embargo, una vez iniciado se convierte en un procedimiento de oficio, lo dirige la Jefatura Zonal que tiene a su cargo el Registro en donde consta un asiento registral presumiblemente sustentado en un título que contiene una presunta falsificación de documentos.

- Remisión de la denuncia a la Jefatura de la Zona Registral correspondiente.

- Actividad de verificación, consistente en la constatación de la presunta falsificación de documento mediante la comunicación, por cualquier medio idóneo (fax, correo electrónico, etc.) y de esta manera procurar obtener una respuesta por escrito del funcionario, autoridad o notario, así como la verificación de la inexistencia de título pendiente de inscripción y que no exista tercero con derecho inscrito protegido por la fe pública registral.

- Emisión de la Resolución Jefatura correspondiente, la misma que debe resolver sobre la procedencia $\mathrm{o}$ 
improcedencia del bloqueo por presunta falsificación de documentos.

- Presentación de la Resolución Jefatura por el diario con la finalidad de generar un número de título para la inscripción del bloqueo por presunta falsificación de documentos, no requiere el pago de tasa registral, ni tampoco la presentación de formulario, debe presentarse al día siguiente de la emisión de la resolución y bajo responsabilidad del Jefe Zonal, respecto a la presentación del formulario, consideramos necesario la presentación del formulario en razón de que es, en ese documento en donde se puede consignar varios datos, y en específico donde se encuentra la rogatoria.

- Anotación del bloqueo por presunta falsificación de documentos a cargo del Registrador Público, previa calificación del título presentado, lo que implica que, en el marco de la norma, el Registrador Público no está obligado a calificar de manera positiva el bloqueo por presunta falsificación de documentos, y contrario sensu, podría calificarla de manera negativa, es decir, podría observar el título, es más podría hasta tachar el título.

- Notificación al funcionario, autoridad o notario a quien es atribuida la emisión del documento, a los titulares con derechos inscritos, a la Procuraduría Pública de la SUNARP y a quien presentó la denuncia.

\section{LA RESOLUCIÓN JEFATURAL}

La Resolución Jefatural que dispone la anotación del bloqueo por presunta falsificación de documentos, deberá contener la siguiente información:

- El asiento registral cuyo título que 1o fundamenta contiene presuntamente el documento falsificado.
- El número de la partida registral (matrícula, o placa única Nacional de rodaje de ser el caso).

- La Oficina Registral y el Registro correspondiente.

\section{CONTENIDO DEL ASIENTO REGISTRAL}

El bloqueo por presunta falsificación de documentos, es una anotación preventiva y tiene la calidad de una carga, el asiento registral deberá contener la siguiente información:

- La denominación de "Anotación de Bloqueo por Presunta Falsificación de Documento".

- Número y fecha de la resolución que dispone la anotación del Bloqueo.

- Nombre del Jefe Zonal que emite la resolución.

- El asiento registral cuyo título que 1o fundamenta contiene presuntamente documento falsificado.

- Indicación del plazo de vigencia de la anotación del Bloqueo.

- Indicación de la Directiva que sustenta la anotación del Bloqueo.

\section{PLAZO Y COMUNICACIÓN A AUTORIDADES}

La anotación del bloqueo por presunta falsificación de documento tendrá una duración de 120 días hábiles, contados desde el día siguiente hábil a la extensión de su anotación en la partida registral por el Registrador Público. Este plazo tiene por finalidad otorgar a los interesados un plazo prudencial para poder realizar las acciones legales que considere conveniente, la cual básicamente será la denuncia penal correspondiente, por el delito de falsificación de documentos.

Por otro lado, una vez realizado el bloqueo por presunta falsificación de documentos, la SUNARP, procederá a realizar diversas notificaciones con la finalidad de que cada una de las personas pueda realizar las acciones 
administrativas y legales que considere conveniente, entre ellas tenemos a:

- Funcionario, autoridad o notario a quien es atribuida la emisión del documento.

- Titulares con derechos inscritos.

- Procuraduría Pública de la SUNARP, y,

- A quien presentó la denuncia.

\section{DESESTIMACIÓN DEL BLOQUEO}

La directiva también regula los supuestos de desestimación de la anotación del Bloqueo por Presunta Falsificación de Documentos, siendo éstos los siguientes:

- Cuando exista título pendiente de inscripción (suspendido, observado, liquidado o tachado con posibilidad de interponerse recurso de apelación ante el Tribunal Registral o interponer acción contenciosa administrativa), siempre que esté vinculado con el asiento registral cuyo título que lo fundamenta contiene presuntamente documento falsificado.

- Cuando exista un tercero con derecho inscrito que se encuentre protegido por la fe pública registral previsto en el artículo 2014 del Código Civil. Sobre este particular es importante tener presente lo comentado por Gálvez Aliaga (2014, p. 185) , cuando nos informa:

"Creemos que el bloqueo por presunta falsificación de documentos solo surtirá efectos de manera residual, por cuanto la mentalidad del falsificador no es que el asiento de inscripción en mérito del documento falso quede perennizado, sino justamente acogerse a las bondades del registro de manera rápida, sin que haya sido detectado el documento falso y que se inscriban actos posteriores para que el asiento de inscripción basado en documento falso quede refundido con asientos válidos $\mathrm{y}$ legítimos"

- Cuando no se pueda determinar la existencia de indicios de falsificación de documentos, y de esa manera, disponer la anotación del Bloqueo, como es el caso de la falta de respuesta por parte de las autoridades a quienes se les solicitó la información, sin embargo, en este último caso consideramos que queda a discreción de la Jefatura Zonal el poder disponer el bloqueo, aun cuando no haya respuesta por parte de las autoridades.

\section{CONCLUSIONES}

-El bloqueo por presunta falsificación de documentos, es una medida que se puede tomar de forma temporal, con la finalidad de poder recurrir al Órgano Jurisdiccional para que se obtenga las medidas cautelares correspondientes.

-El bloqueo por presunta falsificación de documentos, se ha creado con la finalidad de contrarrestar, el fraude inmobiliario que se realiza por las mafias organizadas y que atentan contra la seguridad jurídica que otorga el Registro Público.

-El bloqueo por presunta falsificación de documentos, es un trámite administrativo que se realiza al interior de los Registros Públicos y con efectos en los asientos registrales inscritos aparentemente con documentación falsificada.

-El bloqueo por presunta falsificación de documentos, se tramita cuando se ha presentado la conducta tipificada en el artículo 427 primer párrafo, es decir, cuando se presenta la falsedad material, mas no se aplica a la falsedad ideológica.

\section{REFERENCIAS BIBLIOGRÁFICAS}

-Amado, E. P. (2017). El Derecho Registral y Notarial en la Era Digital. Lima: Ediciones Legales EIRL.

-Bramont-Arias. L. Manual de Derecho Penal. Parte Especial. Lima: Editorial San Marcos.

-Gálvez, I. L. (2014). Manual de Derecho Registral y Notarial. Lima: Editora y Distribuidora Ediciones Legales E.I.R.L. 
-Gonzales, J. L. Comentarios al Nuevo Reglamento General de los Registros Públicos. Lima: Gaceta Jurídica.

-Gonzales, G. (2012). Derecho Registral y Notarial. Jurista Editores. Lima: Jurista Editores.

-Huerta, O. (2003). La Problemática de la Buena Fe del Tercero Registral. Lima: Gaceta Jurídica.

-Moisset, L. (2015). Publicidad Registral. Lima:

SUNARP.
-Peña, R. (1990). Tratado de Derecho Penal. Parte Especial. Lima: Editorial Sagitario.

-Reátegui, J. (2014). Derecho Penal Parte Especial. Lima: Editora y Distribuidora Ediciones Legales E.I.R.L.

-Urtecho, S. E. (2015). El Perjuicio en los Delitos de Falsedad Documental $\left(2^{\circ}\right.$ ed). Lima: Idemsa. 